\title{
The dynamics of one-sided incomplete information in motor disputes
}

\author{
Mercedes Ayuso ${ }^{\dagger}$ \\ Lluís Bermúdez \\ Miguel Santolino ${ }^{\dagger 1}$ \\ ${ }^{\dagger}$ Department of Econometrics, Riskcenter-IREA \\ - Department of Financial and Actuarial Mathematics, Riskcenter-IREA \\ University of Barcelona \\ Avda. Diagonal, 690, 08034 Barcelona, Spain
}

\begin{abstract}
A multi-period negotiation model based on Spier's theoretical model is developed to investigate the optimal strategy of the incompletely informed defendant during the negotiation process in the context of motor bodily injury disputes. More specifically, the paper examines the distribution function of settlements over time in an attempt to explain the time it takes to negotiate the claim compensation. In order to test the assumptions underlying the theoretical model, competing risk models are applied to a Spanish motor insurance database. The empirical analysis yielded two main findings: first, the time to settlement of the claim depends primarily on the degree of informational asymmetry among litigants regarding the magnitude of damages; and second, these asymmetries in information present a dynamic pattern during the negotiation process, since the insurer's incomplete information is enriched during the course of negotiations.
\end{abstract}

\section{Keywords}

Litigation, dispute, cumulative incidence function, settlement delay, private information, mediation.

JEL classification: D81, G22, K4

\footnotetext{
${ }^{1}$ Corresponding author: Department of Econometrics, Riskcenter-IREA, University of Barcelona, Avda. Diagonal, 690, 08034 Barcelona, Spain. Tel. +34 934020 484; fax: +34 934021 821. E-mail address: msantolino@ub.edu (M. Santolino).
} 


\section{Introduction}

In Europe, motor insurance is compulsory for all drivers. Any person sustaining injuries as a consequence of a motor vehicle accident is entitled to compensation for damages from the insurer of the at-fault party. Following an accident, negotiation will usually be initiated between the victim and the insurer - or their respective lawyers - to determine the amount of damages to be paid out. Only when an agreement cannot be reached is the dispute resolved by judicial decision. In the case of motor bodily injuries, most claims are settled by negotiation, with fewer than $5 \%$ of cases in countries such as Spain, the UK or the US being taken to court (Ayuso and Santolino, 2012; Lewis, 2006; Derrig and Rempala, 2006).

The determinants of motor claim compensations and the costs associated with alternative compensation systems have been extensively studied in the literature (Derrig and Weisberg, 2004; Ayuso et al., 2012; Ayuso and Santolino, 2012; Browne and Puelz, 1999; Bell, 2006). Alternative dispute resolution mechanisms have gained popularity in recent years ${ }^{2}$ as a way of achieving motor claim settlements that are more efficient in terms of costs, both private and social, and time to settlement (De Palo, 2013; Doornik, 2014). It is apparent from these reports that the settlement of motor vehicle injury disputes can be lengthy and that the legal process can be slow in many jurisdictions, with the trial date often being fixed several years after legal proceedings have been initiated. In an appreciable number of out-of-court settlements, agreement is not reached until the parties are actually on the courthouse steps (Londrigan, 1984; Deffains and Doriat, 1999). As a result, motor vehicle claims may remain unsettled for several years, regardless of the resolution mechanisms adopted.

Delay in litigation is generally costly (including the expense of hiring lawyers, paying court costs, making interest payments, etc.) and affects both parties to the process. From the insurer's point of view, delay extends uncertainty over long periods, making the computation of adequate provisions essential, while victims are left waiting to receive

\footnotetext{
${ }^{2}$ European Mediation Directive 2008/52/EC, implemented in 2008, seeks to promote ADR mechanisms for the reaching of out-of-court agreements in civil disputes. In Spain, Law 5/2012 on Mediation in Civil and Commercial Disputes was introduced in 2012 to adapt national legislation to the European Directive.
} 
compensation for their injuries. Despite the obvious importance of this matter, the causes of settlement delays have received only scant attention in the literature.

Multi-period bargaining models have been developed to explain why some cases are settled earlier than others and to investigate the optimal strategy of litigants during the negotiation process (Spier, 1992; 2003; Fenn and Rickman, 1999). From a theoretical point of view these models are founded on the notion of one-sided incomplete information, whereby one of the parties has private knowledge regarding the magnitude of damages, and the other party pursues negotiations in order to uncover this private information $^{3}$. The negotiation is extended over several periods during which the incompletely informed litigant makes sequential offers to the informed litigant. Spier's multi-period model is a pioneering strategic bargaining model that addresses the time it takes to settle legal disputes (Spier, 1992). The author focuses on the US litigation system in which the parties have to bear their own legal costs. Fenn and Rickman (1999) adapted Spier's model to account for UK cost allocation rules, where the losing litigant pays the legal costs of both parties.

Inspired by Spier's theoretical model (Spier, 1992) the present research seeks to develop a multi-period bargaining model to explain the time it takes to negotiate the claim compensation in the context of motor bodily injury disputes. In our theoretical framework the degree of informational asymmetry is determined by the level of uncertainty that the defendant has regarding the magnitude of the compensation. An analytical model solution is provided when the uniform distribution is assumed across the range of feasible compensations. Two implications are derived from the distribution function of settlements over time resulting from the theoretical bargaining model: 1) time to settlement is based on the level of compensation uncertainty, and 2) the level of uncertainty does not fluctuate in the course of a negotiation.

This paper combines theory and data to test these two assumptions underlying the theoretical model. The analysis was based on a motor insurance database provided by a leading Spanish insurance company and which reports out-of-court motor vehicle injury settlements. A survival analysis is carried out to determine which factors serve to

\footnotetext{
${ }^{3}$ Bargaining models dealing with two-sided incomplete information are found in the literature but are developed in a timeless framework (Daughety and Reinganum, 1994; Friedman and Wittman, 2007).
} 
explain the delay in motor claim settlements. Competing risk models are applied to estimate the distribution function of settlements over time. Specifically, the semiparametric regression developed by Fine and Gray (1999), and generalized by Scheike and Zhang (2008), is used to model the distribution function of settlements. Severity factors are included in the regression model to analyse the first assumption. The second assumption is investigated by analysing the impact of explanatory factors over time. In the regression analysis, explanatory factors were allowed to have time-varying effects, thereby enabling us to examine whether the presence of such effects provides any insight into time-negotiation patterns. The time-varying effects of the explanatory factors are tested and specific time-functional forms for time-varying effects are studied.

The rest of this paper is structured as follows. In the next section the theoretical bargaining model is examined in the context of motor injury disputes. The empirical analysis is described in section 3, while section 4 discusses the link between the theoretical model and empirical results. Section 5 presents a series of conclusions.

\section{The bargaining model in Spanish motor disputes}

\subsection{Spanish motor disputes}

Here we analyse third-party liability disputes between victims of motor vehicle accidents and the insurance company of the liable driver in Spain. In motor injury disputes strict liability is applied in order to protect the victim, with the driver's liability for causing damage being incurred without it being necessary to prove that he or she was negligent or directly at fault. Therefore, the main conflict usually concerns the amount of damages to be awarded. Following a traffic accident, medical staff from the insurance company examines the victim during the recovery period and evaluates the evolution of his/her injuries. The victim has access to the insurer's medical reports, such that both disputants have similar information regarding the severity of injuries sustained by the victim. However, it is the victim who knows the financial consequences of these injuries. A legislative compensation system is in force to assess motor injury claims, 
and it seeks to reduce uncertainty over compensation payouts ${ }^{4}$. The compensation system is relatively straightforward to apply and involves the recognition of a basic payout to cover general damages in accordance with the severity of the victim's injuries. Correction factors are subsequently applied to adapt this general compensation to the particular circumstances/individual damages (Santolino, 2010; Santolino and Söderberg, 2012).

In order to be entitled to compensation the victim needs to bring charges against the atfault driver, and consequently all motor injury cases are litigated in Spain. Legal proceedings are then initiated and the court manages the case. A timetable is imposed in which the date of the court hearing is fixed by court. Before the date of trial the first option available to the parties is to attempt to reach a friendly agreement regarding compensation for damages. During the negotiation a sequence of bid-demand rounds is played out. The first offer of compensation is typically made by the insurance company based on the medical assessment of the victim's injuries that was carried out by its own medical staff. If this offer satisfies the victim's demands, then a settlement is reached and the negotiation proceedings come to an end. When the offer is rejected the victim may present a counter-demand for compensation or break off negotiations and await the court hearing. When the victim makes a counter-demand the onus shifts back to the insurer, who has the option of accepting the counter-demand, rejecting it and presenting a fresh counter-offer, or awaiting the court hearing. These rounds of negotiation are repeated until a deal is reached, or the date for the court hearing arrives. In the latter case the action is resolved by judicial decision.

\subsection{Theoretical bargaining model}

In this section a one-sided incomplete information multi-period bargaining model based on Spier's model is adapted to the context of motor disputes. Multi-period bargaining models have been developed to analyse the factors that influence settlement timing. Here we follow Spier's modelling approach and assume that a litigant has private information. In Spier's bargaining model it is the defendant who has private information, while the extension of this model suggested by Fenn and Rickman (1999)

\footnotetext{
${ }^{4}$ Scheduled compensation systems exist in many European countries, including France, Belgium, Italy and Ireland (Rogers, 2001).
} 
considers the plaintiff as the informed litigant. As explained above, the victim in Spanish motor disputes knows the non-economic and economic damages sustained as a result of the accident. Denoting the magnitude of damages by $y$, it is hypothesized that the court has the capacity to observe the actual damage sustained by the victim, and it awards the corresponding amount of restitution. Thus, we assume that it is the plaintiff who has private information. Unlike the victim, the insurer (defendant) has incomplete information. In the early stages of the negotiation the insurance company will have an assessment of the victim's injury severity carried out by its own medical staff, but it will not have full knowledge of the total economic and non-economic damages sustained by the victim as a consequence of those injuries.

In this theoretical framework the defendant does not know the magnitude of damages but knows in the initial stage of the negotiation that they are drawn from a known distribution. We postulate that the defendant knows that damages $y$ are drawn from a uniform distribution on $[\underline{y}, \bar{y}]$, where $\underline{y}$ is the minimum compensation the plaintiff would be awarded by the court and $\bar{y}$ the maximum compensation ${ }^{5}$. The only source of asymmetric information considered in the model is the magnitude of the damages, where the range of the interval between the two bounds can be understood as a measure of the insurer's uncertainty. This means that the other characteristics of the accident, including driver's fault, are not issues in dispute, so they have no effect on the timing of the settlement. This simplifying assumption seems to be reasonable in the context of motor bodily injury claims, since strict liability is applied ${ }^{6}$.

The trial date is exogenously fixed and known by litigants. Negotiation takes place over a known time span of $T-1$ periods. If an agreement is not reached, then the compensation is decided at trial in $T$. Let us assume that the defendant makes an offer to the plaintiff in each period of the negotiation. The offer made by the insurer during period $t$ is denoted as $S_{t}$. In a multi-period model the present value of future payments also has to be considered. The litigants discount the future at the same rate $\delta$. Under

\footnotetext{
${ }^{5}$ The uniform distribution is a non-informative distribution, so it is assumed that the insurer does not have prior information related to how damages are distributed on the range $[y, \bar{y}]$. Uniformly distributed damages have frequently been considered in multi-stage bargaining modelling approaches (Spier, 1992; Fenn and Rickman, 1999; Sobel and Takahashi, 1983; Cramton and Tracy, 1992).

${ }^{6}$ Fenn and Rickman (1999) analyse the effect of liability on the conditional probability of settlement, where the percentage of liability is known by litigants.
} 
Spier's framework, offers are forced to be equivalent over time $S_{t}=\delta S_{t+1}$ and lower bounds are then derived according to that restriction. The latter assumption is the main difference between Spier's modelling approach and our framework, since we assume that each time a compensation offer is rejected by the victim, the insurer uses this information to determine the lower bound of compensation in the next period. Therefore, the insurer knows that if $S_{t}$ is rejected, a necessary condition of period $t+1$ is that the damages $y$ are ranged on $\left[\underline{y}_{t+1}, \bar{y}\right]$, where the value of the lower compensation bound $\underline{y}_{t+1}$ is equivalent in financial terms to the offer in the previous period $S_{t}=\delta^{T-t} \underline{y}_{t+1}$.

The defendant is assumed to be risk-neutral. The incompletely informed defendant computes a set of offers that partition the range of compensation payouts, where each offer is designed to minimize the expected payout, given the remaining periods and the fact that plaintiffs with damages below the partition will have accepted earlier offers (Fenn and Rickman, 1999). This optimization problem needs to take into account the litigation costs, since litigation is not free. We assume that the losing litigant has to pay the costs incurred by both parties ${ }^{7}$. The total costs incurred by the plaintiff and by the defendant at the beginning of each period of the negotiation are $c$. The litigants' trial costs are denoted by $k$.

Optimal partitions (see Appendix A) are,

$$
\begin{aligned}
& \underline{y}_{t}^{*}=\underline{y}_{t-1}+\sum_{i=1}^{T-t} \delta^{-i} c+k=\underline{y}_{1}+\sum_{j=1}^{t-1}\left(\sum_{i=1}^{T-(j+1)} \delta^{-i} c\right)+(t-1) k \quad 1<t<T \\
& y_{T}^{*}=\underline{y}_{T-1}+k=\underline{y}_{1}+\sum_{j=1}^{T-2}\left(\sum_{i=1}^{T-(j+1)} \delta^{-i} c\right)+(T-1) k
\end{aligned}
$$

The results can be explained as follows. In each period the optimal offer for the defendant is the sum of the lower bound of feasible damages and the total future costs if the dispute is resolved in trial. Therefore, gains from settlement in a period $t$ are the future costs to be saved in subsequent periods of the settlement process. These optimal partitions are slightly different to Spier's optimal partitions, since under Spier's

\footnotetext{
${ }^{7}$ Under Spanish rules the losing litigant has to pay the costs incurred by both parties (Ayuso and Santolino, 2012), but the model can be adapted to account for situations where parties have to bear their own litigation costs.
} 
framework, gains from settlement in a period $t$ are the costs to be saved solely in the following period ${ }^{8}$.

\subsection{Theoretical implications of the model}

Our focus here is on the distribution function of settlements over time. If the optimal partitions defined in (1) are considered in the numerator of the probability distribution function (pdf) of the uniform random variable $y$, then

$$
\begin{array}{ll}
f\left(\underline{y}_{1}\right)=0 & t=1 \\
f\left(\underline{y}_{t}\right)=\frac{\underline{y}_{t}-\underline{y}_{t-1}}{\bar{y}-\underline{y}_{1}}=\frac{\sum_{i=1}^{T-t} \delta^{-i} c+k}{\bar{y}-\underline{y}_{1}} & 1<t<T \\
f\left(\underline{y}_{T}\right)=\frac{\underline{y}_{T}-\underline{y}_{T-1}}{\bar{y}-\underline{y}_{1}}=\frac{k}{\bar{y}-\underline{y}_{1}} & t=T
\end{array}
$$

and the cumulative distribution function (cdf) is equal to,

$$
\begin{array}{ll}
F\left(\underline{y}_{1}\right)=0 & t=1 \\
F\left(\underline{y}_{t}\right)=\frac{\underline{y}_{t}-\underline{y}_{1}}{\bar{y}-\underline{y}_{1}}=\frac{\sum_{j=1}^{t-1}\left(\sum_{i=1}^{T-(j+1)} \delta^{-i} c\right)+(t-1) k}{\bar{y}-\underline{y}_{1}} & 1<t<T \\
F\left(\underline{y}_{T}\right)=\frac{\underline{y}_{T}-\underline{y}_{1}}{\bar{y}-\underline{y}_{1}}=\frac{\sum_{j=1}^{T-2}\left(\sum_{i=1}^{T-(j+1)} \delta^{-i} c\right)+(T-1) k}{\bar{y}-\underline{y}_{1}} \quad t=T
\end{array}
$$

It should be emphasized that the cdf in (2) does not directly depend on the magnitude of damages. The denominator is computed as the range of the interval between compensation bounds, that is, dispersion, which can be understood as a measure of the insurer's uncertainty. We hypothesize that the spread $\left(\bar{y}-\underline{y}_{1}\right)$ measures the level of uncertainty of the defendant regarding the compensation amount. A higher degree of uncertainty is associated with the defendant as the gap between the two compensation limits becomes larger. Note that the numerator does not depend on the magnitude of damages either, since it is based exclusively on litigation costs. We assume here that

\footnotetext{
${ }^{8}$ Under Spier's framework the model is optimized by $\underline{y}_{t}^{*}=\underline{y}_{1}+\delta^{-T} \sum_{i=1}^{t-1} \delta^{i} c$ and $\underline{y}_{T}^{*}=\underline{y}_{T-1}+k$. For details, see Spier (1992).
} 
litigation costs per period of negotiation are independent of damages. The effect of litigation costs on the cumulative distribution function is not investigated in this article.

From expression (2) a set of assumptions underlying the model can be formulated, as follows:

A1. The time needed to settle cases depends primarily on the uncertainty over the magnitude of damages. Severity of cases does not directly affect the time to settle, such that more severe cases will only take longer if a higher level of uncertainty over damages is involved.

Let us consider two claims with damages $y$ and $z$, such as $E[y]=E[z]$ and $\bar{y}-\underline{y}_{1}>\bar{z}-\underline{z}_{1}$, where $\bar{z}$ and $\underline{z}_{1}$ are the upper and lower bounds of $z$. Both claims involve the same number of negotiation periods and litigation costs. From expression (2) it is shown that $F\left(\underline{y}_{t}\right) \leq F\left(\underline{z}_{t}\right)$ for $t=1, \ldots, T$. Consequently, if $F\left(\underline{y}_{t}\right)>F\left(\underline{z}_{t}\right)$ it must hold that $t^{*}>t$.

Previous studies have shown that more severe cases take longer to settle (Fenn and Rickman, 1999). From expression (2), however, it is postulated that this relationship does not hold in all situations. The expected time to settlement depends on the compensation uncertainty, so more severe cases would take longer to settle if and only if there is greater uncertainty over compensation. The opposite also holds: the time of settlement is expected to be shorter if uncertainty over the amount of damages is negatively associated with injury severity.

A2. The level of uncertainty of the defendant regarding the compensation amount does not fluctuate during the negotiation process.

The insurance company does not know the amount of compensation to be paid out to the victim, but it does know the upper and lower bounds of the payout. In this framework the cumulative incidence function (2) is fixed on the basis of payout bounds. The probability of accepting an offer in a negotiation period is then computed as the distance between the associated partition in that period and the lower bound, in 
comparison with the distance between upper and lower bounds. The relationship between offers and partitions is known, $S_{t}=\delta^{T-t} \underline{y}_{t+1}$. The denominator of the cdf (2) is independent of time, so the level of uncertainty does not fluctuate during the negotiation. Under this assumption the cumulative distribution function of settlements over time is unitarily defined.

\subsection{Negotiation process as a sequence of offers and counter-demands}

In the theoretical framework the negotiation extends over several periods during which the incompletely informed litigant makes sequential offers. Under this framework the problem is optimized assuming that the insurer makes an offer; if it is rejected, then that information is used to determine the lower bound of compensation in the next period in which a new offer is made. However, we noted in section 2.1 that in the real world the negotiation process of motor disputes in Spain is a sequence of bid-demand rounds rather than a simple sequence of offers. Private information is actively disclosed over time during the negotiation as a result of the victim's counter-demands. When the victim makes a counter-demand, incoming information is revealed to the insurer regarding the magnitude of damages. Indeed, the insurer is informed that this amount would be accepted by the victim to settle the claim. The counter-demand is thus the maximum compensation to be offered by a rational insurer. If the insurer rejects the victim's demand, this incoming information should be used by the insurer to compute the upper bound of compensation for the next period. Therefore, in the real world the upper bound of the compensation interval will vary over time $\bar{y}_{t}$ as counter-demands will be made by the victim. This means that the level of the insurer's uncertainty regarding compensation amounts will also fluctuate during the negotiation process $\left(\bar{y}_{t}-\underline{y}_{1}\right)$.

It is necessary, then, to analyse the impact that the inclusion of incoming victim demands has on theoretical solutions. We assume that the insurer does not have prior information regarding the behaviour of the defendant, so the insurer optimizes the problem without considering counter-demands. The model is then sequentially reoptimized as counter-demands are made. At the stage of the negotiation process in which a counter-demand is claimed, the upper bound of feasible compensations is 
readjusted and the problem is re-optimized by taking into account that incoming information. As shown in expression (1), partitions do not depend on the upper bound, so counter-demands would not have an impact on optimal partitions. However, the definition of the cumulative distribution function (2) is conditional on bounds. The distribution function would undergo a readjustment when the upper bound on compensation changes, so a new distribution function would be obtained when bounds are modified. Note that the variation of the upper compensation bound over time is not restricted to a non-positive value. More often than not, victims make a counter-demand that is lower than the previous one, or they maintain the previous demand. However, the variation in the upper bound over time may be positive in some cases. The reasons why the upper bound on compensation might be raised include, among others, the victim suffering a relapse, unexpected additional expenses or more aggressive demands following the substitution of a lawyer.

\section{Empirical analysis}

In this section an empirical analysis is conducted in order to test theoretical assumptions. The time to settlement of claims can be studied by means of survival analysis, which offers a way of examining how the time to settlement in motor disputes is determined by a set of factors for an empirical dataset. Factors associated with the severity of damages are included in the regression model and the impact of these factors on the time to settlement is studied to test the first assumption. In addition, time-varying effects of factors are allowed to verify the second assumption.

\subsection{Competing risk model}

In the context of Spanish motor disputes we have two possible events: out-of-court settlements and judicial adjudication. The occurrence of one event precludes the occurrence of the other. This constitutes the context of competing risks. Let us define the out-of-court settlement as the $1^{\text {st }}$ event and the judicial decision as the $2^{\text {nd }}$ event. Our interest here is in analysing the effect of covariates on the time to settlement. The standard approach for exploring the relationship between the survival of a claim and a 
set of explanatory variables is to model the hazard function by means of the Cox regression model (Cox, 1972). However, this approach has certain drawbacks when dealing with competing risks. The cause-specific hazard function does not have a direct interpretation in terms of the cause-specific distribution function, because it depends on the cause-specific hazards for all the causes. As a result, the effect of covariates on survival probability cannot be readily summarized (Scheike and Zhang, 2008).

Let the distribution function for the $k$-event $F_{k}(t, x)$, also called the cumulative incidence function, be defined as the probability of the occurrence of this event until time $t$ conditional on a set of covariates $x$, in the presence of all possible events. Fine and Gray (1999) suggest a regression method in which $F_{k}(t, x)$ is directly modelled. Let $\lambda_{k}(t, x)$ be the hazard related to the cumulative incidence function, as follows:

$$
\begin{aligned}
\lambda_{k}(t, x) & =\lim _{\Delta t \rightarrow 0} \frac{1}{\Delta t} \operatorname{Pr}\{t \leq T \leq t+\Delta t, \varepsilon=k \mid T \geq t \cup(T \leq t \cap \varepsilon \neq k), x\} \quad k \in\{1,2\} \\
& =-\delta \log \left\{1-F_{k}(t, x)\right\} / \delta t
\end{aligned}
$$

the cumulative distribution function can be modelled on the form,

$$
F_{k}(t, x)=1-\exp \left\{-\exp \left(\beta_{k}^{\prime} x\right) u_{k}(t)\right\} \quad k \in\{1,2\}
$$

where $\beta_{k}$ is a $p$-dimensional vector of parameters and $x$ is the covariate vector. The function $u_{k}(t)$ has the form $u_{k}(t)=\int_{0}^{t} \lambda_{k 0}(s) \delta s$, where $\lambda_{k 0}(t)$ is the baseline hazard for the $k$-th cause. As our focus here is on modelling the cumulative incidence function of out-of-court settlements, the $k$ subscript is withdrawn to simplify notation. This model corresponds to the complementary log-log transformation. In this article we follow the generalization suggested by Sheike et al. (2008), in which a set of covariates is allowed to have time-varying effects,

$$
\operatorname{clog} \log (1-F(t, x))=\beta^{\prime} x+u^{\prime}(t) z
$$


where $z$ is a $(q+1)$ vector of covariates with time-varying effects $\left\{z=\left(1, z_{1}, \ldots, z_{j}, \ldots, z_{q}\right)^{\prime}\right\}$. Note that the regression model (4) reduces to the Fine-Gray model when $z=1$. Estimators for $u(t)$ and $\beta$ are iteratively obtained by solving proper score equations, and confidence bands are computed by means of resampling techniques (for details, see Scheike et al., 2008; Sheike and Zhang, 2008). The hypothesis of timeinvariant effects may be tested by means of a Cramér-von Mises type test (see Martinussen and Sheike, 2006; Sheike and Zhang, 2011).

Specific time-functional forms are analysed for time-varying effects. In this article we consider the linear parametric function for time-varying regressors, as follows:

$$
c \log \log (1-F(t, x))=\beta^{\prime} x+u(t)+u_{a}^{\prime} \times z+u_{b}^{\prime} \times t \times z
$$

where $u_{a}$ and $u_{b}$ are the vector of parameters for the constant and linear part of the time-varying effects, respectively. The parameters can now be easily interpreted. When a specific functional form is considered for the time-varying effects, the partial likelihood principle may be applied to obtain the parameter estimates (Gray, 1988; Fine and Gray, 1999).

In the context of legal disputes, competing risk models have previously been used by Fenn and Rickman (2013). Their study provides an empirical analysis, using competing risk models, of factors leading to the decision to drop or settle medical malpractice disputes over time. They investigated the relationship between time to resolution and the information about case strength, and found that cases involving little uncertainty, because they are either relatively weak or relatively strong, are resolved faster. Unlike this previous study, the explanatory factors in our regression analysis were allowed to have time-varying effects.

\subsection{Data}

Motor vehicle insurance data were provided by one of the leading motor car insurance companies operating in Spain. The dataset comprises a random sample of 5,000 victims who sustained injuries in traffic accidents in Spain, of which 4,781 claims were settled 
by negotiation between the insurer and the plaintiff and 219 were resolved by judicial decision. All the victims in the sample received compensation in 2007. However, only 28 per cent of accidents occurred in 2007, with 57 per cent being recorded in 2006 and 15 per cent in 2005 or earlier. The victims had to be fully recovered or their injuries had to be stabilized before they could be compensated by the insurer. The time taken for the victim to recover was not included in the assessment of the duration of the settlement process. Thus, the duration was computed as the time between the date that the claim was settled and the date that the victim was deemed to be fully recovered from his or her temporary injuries, rather than the date on which the claim was made. In this way the potential endogeneity between the duration of the settlement process and the time taken by the victim to recover from his or her injuries is avoided.

The information regarding the claim (and included here in our dataset) was collected by the insurance company during the insurance claims process. The description of the variables and their associated descriptive statistics are shown in Table 1. The claims in the sample took an average of 224.35 days to be settled. However, major differences can be observed depending on the resolution mechanism employed. Claims resolved by judicial decision took on average 649.61 days, with a standard deviation of 282.44 days. For out-of-court settlements the mean duration of the negotiation process was 204.86 days with a standard deviation of 179.58 days. The explanatory variables are classified as general factors, factors related to the region of the body where the injury was recorded and factors related to the severity of these injuries.

The general factors include the socio-demographic characteristics of the victim, such as age and gender, and victim type (i.e. role in accident). We hypothesize that the bargaining behaviour of the victims may be associated with their age and gender and, therefore, the length of time to settlement might, in part, be explained by these factors. The previous literature has reported the relationship between risk behaviour and the demographic features of agents (Ayuso et al., 2012; Doerpinghaus et al., 2008; Halek and Eisenhauer, 2001). Likewise, the victim's behaviour in the negotiation may also be conditioned by type. Note that we classify victims according to the following types: driver, at-fault automobile passenger, no-fault automobile passenger, and pedestrian or 
cyclist ${ }^{9}$. The victim's attitude can be expected to differ depending on whether he or she was a passenger in the at-fault automobile or otherwise. Indeed, Derrig and Weisberg (2004) claim that passengers of the at-fault automobile seek lower settlements because of a 'familiarity effect'. In the case of non-motorized road users, previous studies have shown that cyclists and pedestrians suffer more serious injuries than do car occupants, and so they obtain higher compensation settlements (Pucher and Dijkstra, 2003; Ayuso et al., 2012). Here, we investigate whether longer settlement times are also expected in these cases.

\section{Table 1. Description of variables and statistics}

\begin{tabular}{|c|c|c|c|c|c|}
\hline Variable & Description & Mean & SD & Min. & Max. \\
\hline \multicolumn{6}{|l|}{ Dependent variable } \\
\hline Duration & Length of claim settlement (number of days of claim settlement) & 224.346 & 206.397 & 0 & 2517 \\
\hline Procedure & $\begin{array}{l}1 \text { if the compensation is agreed by negotiation; } 2 \text { if the compensation is } \\
\text { awarded by judicial decision. }\end{array}$ & 1.0438 & 0.205 & 1 & 2 \\
\hline \multicolumn{6}{|l|}{ Regressors } \\
\hline \multicolumn{6}{|l|}{ General factors } \\
\hline Victim's age & Age of the victim & 37.778 & 16.659 & 2 & 98 \\
\hline Gender & 1 if the injured victim is male; 0 otherwise. & 0.455 & 0.498 & 0 & 1 \\
\hline Driver & 1 if the injured victim was the driver; 0 otherwise. & 0.496 & 0.487 & 0 & 1 \\
\hline At-fault Passenger & 1 if the injured victim was the passenger in at-fault vehicle; 0 otherwise. & 0.213 & 0.409 & 0 & 1 \\
\hline No-fault Passenger & $\begin{array}{l}1 \text { if the injured victim was the passenger in no-fault vehicle; } 0 \\
\text { otherwise. }\end{array}$ & 0.166 & 0.372 & 0 & 1 \\
\hline Pedestrian/Cyclist & 1 if the injured was a non-motorized road user; 0 otherwise. & 0.125 & 0.330 & 0 & 1 \\
\hline \multicolumn{6}{|c|}{ Factors related to the injured body region } \\
\hline Head & 1 if injury located in head; 0 otherwise. & 0.131 & 0.338 & 0 & 1 \\
\hline Neck & 1 if injury located in neck; 0 otherwise. & 0.681 & 0.466 & 0 & 1 \\
\hline Upper torso & 1 if injury located in upper torso (thorax/dorsal); 0 otherwise. & 0.242 & 0.428 & 0 & 1 \\
\hline Lower torso & 1 if injury located in lower torso (abdomen/lumbar); 0 otherwise. & 0.195 & 0.396 & 0 & 1 \\
\hline Upper extremities & 1 if injury located in upper extremities; 0 otherwise. & 0.265 & 0.441 & 0 & 1 \\
\hline Lower extremities & 1 if injury located in lower extremities; 0 otherwise. & 0.257 & 0.437 & 0 & 1 \\
\hline \multicolumn{6}{|c|}{ Factors related to the severity of injuries } \\
\hline Score & Severity score of permanent injuries (divided by 100) & 0.043 & 0.075 & 0 & 1 \\
\hline Hospital days & Number of recovery days in hospital (divided by 100 ) & 0.019 & 0.111 & 0 & 4.51 \\
\hline Disabled days & $\begin{array}{l}\text { Number of out-patient recovery days with disability for working } \\
\text { (divided by 100) }\end{array}$ & 0.759 & 0.756 & 0 & 7.31 \\
\hline Non-disabled days & $\begin{array}{l}\text { Number of out-patient recovery days without disability for working } \\
\text { (divided by } 100 \text { ) }\end{array}$ & 0.281 & 0.405 & 0 & 3.96 \\
\hline
\end{tabular}

\footnotetext{
${ }^{9}$ Motor insurance is third-party liability and, therefore, the at-fault driver is the only victim of a traffic accident not entitled to compensation for injuries sustained.
} 
Information regarding injuries is included in the remaining factors. This information is based on medical assessments carried out by the insurance company's own medical experts during the period of recovery. Injuries are grouped according to body region and their severity. In the case of body region, we analyse the influence on settlement duration of injuries to the head, neck, upper torso, lower torso, upper extremities and lower extremities. Some types of injury might be associated with greater uncertainty regarding compensation payouts. For instance, a higher probability of fraudulent damages or unpredictability in non-economic damages for pain and suffering is related to some injuries, although this issue is beyond the scope of this paper.

The last four factors concern the severity of the injury, the aim being to investigate the effect of case severity on the length of the settlement process. The score factor captures the degree of severity of permanent injuries and is stated in accordance with a legal medical scale. The aggregate score for injuries has an upper bound of 100 points, with a high score being indicative of a more serious permanent injury. Temporary disabilities are captured by three variables: time spent recovering in hospital, the out-of-hospital recovery period during which the victim is on sick leave, and the recovery period during which the victim is able to work but is still receiving some form of out-patient therapy.

\subsection{Results}

The model regression (4), with one set of covariates with time-varying effects and another set with constant effects, is fitted to the data to estimate the cumulative incidence function. Hypothesis testing was carried out in order to select the nonparametric term of the regression model. We began by applying a non-parametric model in which it is assumed that all variables have time-varying effects. The significance of the non-parametric effects $u(t)$ was tested, firstly, by examining whether an effect of a covariate is significantly different to zero: $H_{0}: u_{j}(t)=0 t \in[0, \tau]$, for $j=0, \ldots q$, where $\tau$ is the point in time at which the study is conducted. Second, the Cramér-von Mises test was computed to analyse whether or not the effect varies with time: $H_{0}: u_{j}(t)=u_{j}$ $t \in[0, \tau]$. Covariates with significant time-varying effects at the $5 \%$ level were selected for the non-parametric term. We found that the covariate capturing the age of the victim showed a significant and varying effect with time. Similarly, all four factors related to 
the severity of injuries were statistically significant and had strong time-varying effects. Estimates of time-varying effects and the $95 \%$ confidence intervals of the covariates are plotted in Appendix B (Figure B.1).

Specific time-parametric functional forms are investigated for those covariates with associated significant time-varying effects. When the analysis of the effect of the regressors is a main issue, some caution is recommended in the interpretation of estimated coefficients associated with highly correlated regressors. Multicollinearity between regressors may have an effect on the value of coefficient estimates. The severity score for permanent injuries and the length of time recovering from temporary injuries - days hospitalized, disability from work and out-of-hospital but able to work are candidates for being highly correlated. Correlation coefficient estimates of injury severity factors are shown in Table 2.

Table 2. Correlation matrix of severity factors

\begin{tabular}{c|cccc} 
& Score & Hospital days & Disabled days & Non-disabled days \\
\hline Score & 1 & $0.565^{*}$ & $0.600^{*}$ & -0.014 \\
Hospital days & & 1 & $0.330^{*}$ & -0.020 \\
Disabled days & & & 1 & $-0.234^{*}$ \\
Non-disabled days & & & & 1 \\
\hline$* 5 \%$ significance level & &
\end{tabular}

The model regression (5) is fitted to the data, where linear time-functions were analysed for the time-varying effects. Note that the Score factor is highly correlated with the Hospital days and Disabled days factors. To avoid multicollinearity, only the Score factor was included in the regression model. The criterion for selecting the Score factor was the greater explanatory capacity of this factor versus the Hospital days and Disabled days factors, in terms of the increase in the pseudo-log likelihood ${ }^{10}$. The Nondisabled days factor was included since it does not show a significant correlation with the Score factor. Parameter estimates are shown in Table 3.

\footnotetext{
${ }^{10}$ An alternative action to deal with multicollinearity would be to group correlated factors, but they are not expressed in the same units of measure so the construction of an indicator would be required and the interpretation of the effect would be more complex.
} 
Table 3. Cumulative incidence function of the settlement process duration

\begin{tabular}{clccc}
\hline \multicolumn{1}{c}{ Variable } & \multicolumn{1}{c}{ Label } & Coeff. & Estim. & p-value \\
\hline Constant effects & & & \\
$x_{1}$ & Gender & $\beta_{1}$ & -0.011 & 0.730 \\
$x_{2}$ & Passenger in no-fault vehicle $\left.{ }^{*}\right)$ & $\beta_{2}$ & 0.066 & 0.087 \\
$x_{3}$ & Passenger in at-fault vehicle $\left(^{*}\right)$ & $\beta_{3}$ & 0.266 & 0.000 \\
$x_{4}$ & Pedestrian/Cyclist $\left({ }^{*}\right)$ & $\beta_{4}$ & 0.071 & 0.160 \\
$x_{5}$ & Head & $\beta_{6}$ & -0.078 & 0.081 \\
$x_{6}$ & Neck & $\beta_{7}$ & 0.131 & 0.000 \\
$x_{7}$ & Upper torso & $\beta_{8}$ & 0.198 & 0.000 \\
$x_{8}$ & Lower torso & $\beta_{9}$ & 0.109 & 0.006 \\
$x_{9}$ & Upper extremities & $\beta_{10}$ & 0.119 & 0.000 \\
$x_{10}$ & Lower extremities & $\beta_{11}$ & 0.079 & 0.033 \\
Time-varying effects & & & \\
$z_{1}$ & Victim 's age & $u_{1}$ & 0.068 & 0.000 \\
$z_{1} \times t$ & Victim's age by time & $u_{1.1}$ & $-0.002 \times 10^{-2}$ & 0.000 \\
$z_{2}$ & Score & $u_{2}$ & -2.980 & 0.000 \\
$z_{2} \times t$ & Score by time & $u_{2.1}$ & 0.004 & 0.000 \\
$z_{3}$ & Non-disabled days & $u_{2}$ & 0.249 & 0.000 \\
$z_{3} \times t$ & Non-disabled days by time & $u_{2.1}$ & $-0.04 \times 10^{-2}$ & 0.069 \\
& & & & \\
\hline
\end{tabular}

$\mathrm{N}=5,000$. Pseudo log-likelihood: $-\mathbf{3 6 , 4 9 7}$

(*) Base category is driver.

Now, the cumulative distribution function of time of settlements can be estimated on the basis of the value of the set of regressors shown in Table 3. A positive coefficient indicates that if the variable takes a higher value, ceteris paribus, the probability of a settlement being reached increases and, therefore, we can expect a shorter settlement process. The opposite also holds. When the coefficient is negative, the settlement process is expected to be longer for higher values of the covariable. Covariates with time-varying effects indicate that the impact of the regressor on the cumulative distribution function changes over time. These regressors take the same value during the motor dispute, but the effect of these covariates on the cumulative incidence function depends on the point in the negotiation process that comes under consideration.

Let us first briefly discuss factors presenting constant estimated effects. We did not find significant differences in the expected length of time to settlement in function of the gender of the victim. As for victim-type, the probability of settling the claim before a 
certain date increases if the victim is a passenger rather than the driver. The remaining victim-type factors did not present significant coefficients, so differences between drivers and cyclists or pedestrians in the expected length of time to settlement were not found. To conclude, factors related to the region of the body suffering injury present positive coefficients, except for the factor indicating that the injuries were to the head, where the coefficient is significant at the 10 per cent level and negative. Therefore, the probability of settling the claim before a certain time falls when the victim sustains injuries to the head. This region is particularly prone to serious injury.

Finally, we focus on time-varying effects. The positive coefficient of the victim's age factor indicates that the age of the victim is inversely related to the expected length of time to settlement. This result indicates that negotiations are expected to be shorter as the victim's age increases. However, the effect of age on the cumulative incidence function is not constant over time. Indeed, the factor that captures the interaction of time with age presents a negative coefficient. The two coefficients of the factors associated with age should be interpreted jointly when the effect of the victim's age comes under analysis. The effect of age on the cumulative incidence function is positive - i.e. the settlement timing can be expected to be shorter - but it decreases in tandem with prolongation of the negotiation process.

Note that the factor associated with the severity score presents a negative coefficient. As such, the length of the claim settlement is expected to be greater in the case of those victims who sustained the most severe permanent injuries. This injury severity factor has time-varying effects, so the initial effect of this factor on the settlement process is attenuated with time. Higher values for this factor initially increase the expected length of time to settlement, but the effect is diluted as negotiations progress. It should be emphasized that temporary injuries affect the settlement timing in the opposite direction. The factor capturing information related to the victims' out-of-hospital recovery period presents a positive coefficient. As such, shorter negotiations are initially expected for victims who spend longer periods recovering out-of-hospital, during which time they were able to work. Note that the interaction of this factor with time shows a significant coefficient at the 10 per cent level and is negative, so the effect of this factor on the cumulative incidence function is attenuated with time. 


\section{Discussion}

In the theoretical framework the cumulative distribution function (2) was determined by litigation costs and the range of feasible compensation amounts, which was understood as a measure of the insurer's uncertainty. We claimed in the assumption underlying the model (A1) that the time to settle depends on uncertainty over the magnitude of damages rather than on the severity of injuries, and, consequently, more severe cases do not always take longer to settle. Evidence in support of this assumption was provided by the empirical model. There we found that the length of the claim settlement was greater in the case of victims who sustained the most severe permanent injuries and injuries to the head. However, the severity factor capturing information related to the victims' outof-hospital recovery period during which they were able to work was shown to be negatively associated with the time to settlement. Therefore, shorter negotiations were expected for victims who spent longer periods recovering out-of-hospital and during which time they were able to work.

Outcome results from the empirical model are interpreted here in terms of how regressors act on the range of feasible damages. Thus, the sign of regressor coefficients indicates the direction of the effect on the level of insurer uncertainty regarding the compensation amount of the case. Our results suggest that compensation uncertainty increases in line with the severity factors associated with permanent injuries and injuries to the head, widening the interval between the compensation limits. As uncertainty over damages is the only source of asymmetric information, these findings are consistent with the literature which suggests that case complexity depends positively on the severity of damages (Shavell, 2004; Santolino and Söderberg, 2012).

In terms of the effect of the factor associated with temporary injuries on the time to settle, the results indicate that the width of the interval is reduced by this factor, due to a lower degree of uncertainty regarding the amount of compensation. Under the Spanish system, victims are entitled to financial compensation for each day spent recovering from their injuries. The system stipulates a unitary compensation per day spent recovering when the victim is deemed fit to work. Victims are not required to prove they suffered damages in order to be entitled to basic compensation for the out-of- 
hospital recovery period. In addition, victims are entitled to claim higher compensation for the period of disability than the legally stipulated amounts, although in this case they have to provide proof of damages. This basic compensation for temporary disabilities caused by motor accidents is compatible with other forms of compensation, including salary paid by the employer, or unemployment or retirement benefits. Our results can be explained by the fact that basic compensation per day would, in general, be perceived by victims as being sufficient to cover the injuries sustained and, consequently, compensation uncertainty is not increased with this factor ${ }^{11}$.

We found no differences between drivers and cyclists or pedestrians in the expected length of time to settlement. However, it has been shown in the literature that these types of motor accident victims suffer more serious injuries (Pucher and Dijkstra, 2003; Ayuso et al., 2012). This result would support the assumption that more severe cases do not necessarily take longer to settle. Longer negotiations were expected when plaintiffs were drivers rather than passengers. Drivers might be associated with a greater propensity for confrontation as a result of their having suffered greater non-economic damage (e.g. the victim required the vehicle involved in the accident for his/her daily life, such as doing the school run, going to work, etc.). As a result, more aggressive demands would be made by drivers, and therefore greater uncertainty over the magnitude of damages would be associated with them.

An interesting result when comparing types of passengers is that a greater reduction in the settlement survival function is observed when the victim is a passenger in the atfault vehicle. This result would support the idea that passengers in the at-fault automobile accept lower settlements due to the 'familiarity effect' (Derrig and Weisberg, 2004). In order to be entitled to compensation, passengers in the at-fault automobile have to bring a legal suit against the driver, who is usually a relative or friend. As a result, a lesser propensity for confrontational behaviour when seeking shorter negotiations tends to be associated with passengers in the at-fault automobile.

We will now discuss the second assumption underlying the model (A2), namely that the level of uncertainty regarding the compensation amount does not fluctuate during the

${ }^{11}$ In 2013 the basic compensation paid per day spent recovering out-of-hospital when the victim is deemed fit for work was 31.34 euro. 
negotiation process. In the theoretical framework the negotiation process was defined as a sequence of offers by the insurer. Under this framework the level of uncertainty, measured as the distance between payout bounds $\left(\bar{y}-\underline{y}_{1}\right)$, was constant over the process. The cumulative distribution function (2) was then unitarily defined, as it is fixed on the basis of compensation bounds. In section 2.4 we argued that the inclusion of victim counter-demands in the theoretical framework had an impact on the cumulative distribution function. As incoming information is provided along with counter-demands, upper bounds are recomputed, and so the cumulative distribution function is altered. In the empirical regression analysis carried out in the previous section, factors with time-varying effects indicate that the cumulative distribution function of time to settlement varies over the negotiation process. Our claim here is that regressors with time-varying effects would reflect the fact that the bargaining process consists of rounds of offers and counter-demands. This interpretation based on timevarying effects is consistent with the idea that insurer uncertainty fluctuates with incoming victim demands.

Although outcome results indicate that longer negotiations were expected with younger victims, the effect of age was not constant over the negotiation process. This result suggests that the age of the victim is related to his/her bargaining behaviour, thereby affecting the level of uncertainty over damages. A potential explanation for this is that the victim's tendency to display confrontational behaviour decreases with age (Doerpinghaus et al., 2008). We interpret the time-varying age factors as being young victims who initially make high settlement claims and who also make proportionally greater reductions in their subsequent demands as these are rejected by the insurance company. A possible explanation would seem to be that while young victims initially make more aggressive demands, they then have to reduce their pretensions drastically as their demands are rejected by the insurer. This interpretation is consistent with the hypothesis that the insurer's incomplete information is enriched during negotiation, as counter-demands are made by the victim.

Injury severity factors also showed time-varying effects. The severity of permanent injuries increased the expected length of time to settlement, although the effect was diluted as negotiation progressed. As for the severity of temporary injuries, this factor 
was negatively related with the survival distribution, but here again the effect was gradually attenuated over the negotiation. The effect of these factors over time supports the idea that incoming information about damages is provided by victims to insurers during the negotiation process. Initially the severity of injuries is positively related with the survival distribution, but this effect is gradually attenuated as incoming information is provided. In relation to temporary injuries, we hypothesize that victims who remain in the negotiation process after the initial rounds tend to be those for whom the basic legal compensation paid per day is insufficient to meet their actual damages and, therefore, the uncertainty regarding compensation is heightened.

\section{Conclusions}

In this article we develop a multi-period bargaining model inspired by the pioneering model of Spier and adapted to the context of motor bodily injury disputes. An optimal solution and the distribution function of settlements over time are derived for this theoretical bargaining model. From the cumulative distribution function of settlements over time, two assumptions underlying the model may be considered: 1) time to settlement is based on the level of compensation uncertainty, and 2) the level of uncertainty does not fluctuate in the course of a negotiation.

Competing risk models were applied to a motor insurance database to test these two assumptions. Our empirical findings support the first assumption that the time of settlement depends primarily on the degree of uncertainty expressed by the insurer regarding the injuries or damages actually sustained by the victim. The second assumption, by contrast, is not borne out by the evidence, since the results suggest that the insurer's uncertainty is attenuated over time.

Regarding the first assumption, we found, in most cases, that claims involving more severe injuries are characterized by longer settlement delays, thereby indicating greater uncertainty regarding compensation. However, this was not always the case, as we also found that longer recovery periods (involving temporary out-of-hospital disabilities during which time the victim is able to work) do not increase the delay in the awarding 
of compensation. We attribute this to the fact that the compensation for temporary outof-hospital disabilities is legally stipulated. In such instances, therefore, the Spanish legal system would fulfil the goal - which is explicitly mentioned in the preamble to the legislative act - of reducing uncertainty regarding compensation.

As far as the second assumption is concerned, time-varying effects were observed for the explanatory factors related to the victim's age and the severity of his or her injuries. The effect of these factors on the survival function is diluted for longer negotiation processes, suggesting that the degree of informational asymmetry presented by the insurer decreases during the negotiation. We hypothesized under this framework that the claim duration depends on the degree of one-sided informational asymmetry, which fluctuates during the negotiation process. The initial dispute negotiation process can be interpreted as a sequence of rounds of offers and counter-demands. In each round the litigant with incomplete information (the insurer) makes a compensation offer and, if it is not accepted, the litigant with private information (the victim) makes a counterdemand. In this way, the extent of one-sided incomplete information is rapidly reduced as a result of the incoming information provided by the victim.

Although the second assumption seems not to be validated by our empirical findings, we show that our bargaining model is easily adapted to this circumstance. At the beginning of the negotiation process the insurer does not know whether counterdemands will be made in the event of the victim rejecting an offer, and nor would information be available regarding the size of any such demand. Consequently, the insurer optimizes the problem without considering counter-demands. At the point in the negotiation process when a counter-demand is made, we assume that the upper bound of feasible compensations is readjusted. Hence, the problem is re-optimized by taking into account this incoming information.

To sum up, two main findings may be considered here. First, in some cases the severity of temporary injuries was found to be negatively associated with the time to settlement of the claim, suggesting that more severe cases do not always take longer to settle; this supports the assumption that the time to settlement depends primarily on the uncertainty over the magnitude of damages. Second, time-varying effects were observed for the explanatory factors related to the victim's age and the seriousness of injuries. The effect 
of these factors on the time to settlement of the claim is attenuated over time, suggesting that the level of uncertainty fluctuates in the course of negotiations due to the fact that the insurer's incomplete information is enriched as a consequence of the victim's counter-demands.

Various policy implications can be derived directly from our findings. A directive has been implemented in Europe to promote the application of alternative dispute resolution mechanisms so that out-of-court agreements can be reached in civil disputes. The theoretical multi-period bargaining model presented here is based on the assumption that the time needed to reach a settlement depends on how quickly the informational asymmetries between the litigant parties are reduced. Our results indicate that there could be room for mediation/arbitration mechanisms to reduce delays in insurance settlements provided the representatives of the impartial party are able to attenuate informational asymmetries between litigants at a faster rate than is possible by direct negotiation.

\section{Acknowledgments}

We express our gratitude to the editor and referees for their most valuable comments. The authors are grateful to the Spanish Ministry of Economy and Competitiveness for grant ECO2012-35584. 


\section{APPENDIX A}

Let $V_{\left(T-t, \underline{y}_{t}, \bar{y}\right)}$ be the defendant's expected payoff at period $t$, where $(T-t)$ is the number of remaining negotiation periods and $\underline{y}_{t}$ is the lower bound of compensation, for $t=1, \ldots, T$. First we analyse the model for a settlement time span of two periods $(T=2)$. The defendant knows that damages $y$ are in the range $\left[\underline{y}_{1}, \bar{y}\right]$. In the one-shot game the objective function to optimize is $V_{(1, \underline{1}, \bar{y})}=\operatorname{Pr}\left(S_{1}\right) \cdot S_{1}+\operatorname{Pr}\left(\bar{S}_{1}\right) \delta \cdot(T C+k)+c$, where $\operatorname{Pr}\left(S_{1}\right)$ and $\operatorname{Pr}\left(\bar{S}_{1}\right)$ are the probabilities of the plaintiff accepting or rejecting $S_{1}$, respectively, and $T C$ is the expected court-awarded compensation. Note that damages are uniformly distributed in the range $\left(\bar{y}-\underline{y}_{1}\right)$, so $\operatorname{Pr}\left(S_{1}\right)=\left(\frac{\underline{y}_{2}-\underline{y}_{1}}{\bar{y}-\underline{y}_{1}}\right)$, $\operatorname{Pr}\left(\bar{S}_{1}\right)=1-\operatorname{Pr}\left(S_{1}\right)=\left(\frac{\bar{y}-\underline{y}_{2}}{\bar{y}-\underline{y}_{1}}\right)$ and $T C=\frac{\bar{y}+\underline{y}_{2}}{2}$. The objective function

$$
\begin{aligned}
V_{\left(1, \underline{y}_{1}, \bar{y}\right)} & =\left(\frac{\underline{y}_{2}-\underline{y}_{1}}{\bar{y}-\underline{y}_{1}}\right) S_{1}+\left(\frac{\bar{y}-\underline{y}_{2}}{\bar{y}-\underline{y}_{1}}\right) \delta\left(\frac{\bar{y}+\underline{y}_{2}}{2}+k\right)+c \\
& =\left(\frac{\delta^{-1} S_{1}-\underline{y}_{1}}{\bar{y}-\underline{y}_{1}}\right) S_{1}+\left(\frac{\bar{y}-\delta^{-1} S_{1}}{\bar{y}-\underline{y}_{1}}\right) \delta\left(\frac{\bar{y}+\delta^{-1} S_{1}}{2}+k\right)+c
\end{aligned}
$$

is minimized by the offer $S_{1}^{*}=\delta\left(\underline{y}_{1}+k\right)$ and, then, $\underline{y}_{2}^{*}=\underline{y}_{1}+k$.

We now analyse the model for a time span of three periods $(T=3)$. Therefore, the defendant must offer a first amount $S_{1}$, and, if it is rejected by the victim, must make a second offer $S_{2}$ in the next negotiation period. A necessary condition of this game is that $\delta^{-2} S_{1}=\underline{y}_{2}$ and $\delta^{-1} S_{2}=\underline{y}_{3}$, so plaintiffs with damages in the range $\left(\underline{y}_{t+1}-\underline{y}_{t}\right)$ will accept the compensation offer $S_{t}$, for $t=1,2$. In the first period the defendant's optimal first-period offer $S_{1}$ must minimize the expected payoff $V_{\left(2, \underline{y}_{1}, \bar{y}_{1}\right)}$ which is given by,

$$
V_{\left(2, \underline{y}_{1}, \bar{y}\right)}=\operatorname{Pr}\left(S_{1}\right) \cdot S_{1}+\operatorname{Pr}\left(\bar{S}_{1}\right) \delta \cdot V_{\left(1, \underline{y}_{2}, \bar{y}\right)}+c
$$


where $V_{\left(1, \underline{y}_{2}, \bar{y}\right)}$ is the expected payoff in the second period of negotiation $(t=2)$, which is equal to

$$
\begin{aligned}
V_{\left(1, \underline{y}_{2}, \bar{y}\right)} & =\operatorname{Pr}\left(S_{2}\right) \cdot S_{2}+\operatorname{Pr}\left(\bar{S}_{2}\right) \delta \cdot(T C+k)+c \\
& =\left(\frac{\underline{y}_{3}-\underline{y}_{2}}{\bar{y}-\underline{y}_{2}}\right) S_{2}+\left(\frac{\bar{y}_{2}-\underline{y}_{3}}{\bar{y}-\underline{y}_{2}}\right)\left(\frac{\bar{y}+\underline{y}_{3}}{2}+k\right)+c .
\end{aligned}
$$

The model is sequentially optimized. The one-shot model implies that the offer made by the defendant to the victim in the second period $(t=2)$ is equal to the discounted sum of the lower bound and trial costs $S_{2}=\delta\left(\underline{y}_{2}+k\right)$. Hence, expression (A1) is optimized for the first-period strategic offer $S_{1}^{*}=\delta^{2}\left(\underline{y}_{1}+\delta^{-1} c+k\right)$ and optimal partitions are equal to $\underline{y}_{2}^{*}=\underline{y}_{1}+\delta^{-1} c+k$ and $\underline{y}_{3}^{*}=\underline{y}_{1}+\delta^{-1} c+2 k$. Let us now extend the negotiation to $T$ periods, such that optimal partitions are as shown in (1). 


\section{APPENDIX B}

Figure B.1. Estimates of time-varying effects (solid lines) with $95 \%$ confidence intervals (broken lines)

[INSERT FIGURES] 


\section{REFERENCES}

Ayuso, M., L. Bermúdez, and M. Santolino, 2012. "Influence of the parties' behavioural features on motor compensation outcomes" Journal of Risk Research, 15 (6): 673-691.

Ayuso, M., and M. Santolino, 2012. "Forecasting the maximum compensation offer in the automobile BI claims negotiation process" Group Decision and Negotiation, 21 (5): 663-672.

Bell, P., 2006. "The Social Construction of Bodily Injury" The Geneva Papers on Risk and Insurance - Issues and Practice, 31: 340-356.

Browne, M.J., and R. Puelz, 1999. "The effect of legal rules on the value of economic and non-economic damages and the decision to file" Journal of Risk and Uncertainty, 18 (2): 189-213.

Cox, D., 1972. "Regression Models and Life Tables" Journal of the Royal Statistical Society B, 34: 187-220.

Cramton, P., and J. Tracy, 1992. "Strikes and Holdouts in wage bargaining: theory and data" American Economic Review, 82: 100-121.

Daughety, A., and J. Reinganum, 1994. "Settlement Negotiations with Two-sided Asymmetric Information: Model duality, Information distribution and Efficiency" International Review of Law and Economics, 14: 283-298.

Deffains, B., and M. Doriat, 1999. "The Dynamics of Pretrial Negotiation in France: Is there a Deadline Effect in the French legal System?" International Review of Law and Economics, 19: 447-470.

De Palo, G. 2013. "The Cost of Not-Using Mediation”, Mediation as an Alternative Dispute Resolution Method in Insurance Conflicts: New Scenarios under the Law 5/2012, January 24, Barcelona, Spain.

Derrig, R.A., and G.A. Rempala, 2006. "A statistical analysis of the effect of anchoring in the negotiation process of automobile bodily injury liability insurance claims" $C A S$ Predictive Modelling Seminar, October 4, Boston, MA.

Derrig, R., and Weisberg, 2004. "Determinants of total compensation for auto bodily injury liability under no-fault: investigation, negotiation and the suspicion of fraud" Insurance and Risk Management, 71 (4): 633-662.

Doerpinghaus, H., J. Schmit, and J. Yeh, 2008. "Age and gender effects on auto liability insurance payouts" Journal of Risk and Insurance, 75 (3): 527-550.

Doornik, K. 2014. "A rationale for mediation and its optimal use" International Review of Law and Economics, 38, 1-10.

Fenn, P., and N. Rickman, 1999. "Delay and Settlement in Litigation" The Economic Journal, 109: 476-491. 
Fenn, P., and N. Rickman, 2013. "Information and the Disposition of Medical Malpractice Claims: A Competing Risks Analysis" Journal of Law, Economics and Organization, in press. doi: 10.1093/jleo/ewt002.

Fine, J., and R. Gray, 1999. "A Proportional Hazards Model for the Subdistribution of a Competing Risk" Journal of the American Statistical Association, 94 (446): 496-509.

Friedman, D, and Wittman, 2007. "Litigation with Symmetric Bargaining and TwoSided Incomplete Information" Journal of Law, Economics, and Organization, 23: 98126.

Gray, R., 1988. "A Class of K-Sample Tests for Comparing the Cumulative Incidence of a Competing Risk" Annals of Statistics, 16 (3): 1141-1154.

Jeong, J-H, and J. Fine, 2007. "Parametric regression on cumulative incidence function" Biostatistics, 8 (2): 184-196.

Lewis, R., 2006. "How important are insurers in compensating claims for personal injury in the UK?" Geneva Papers on Risk and Insurance-Issues and Practice, 31 (2): 323-339.

Londrigan, T., 1984. "Prejudgment Interest: Is There Profit in Court Delay - Plaintiff's Opinion" The Judges' Journal, 4: 12-49.

Martinussen, T., and T. Sheike, 2006. Dynamic Regression Model for Survival Data. New York: Springer.

Pucher, J., and L. Dijkstra, 2003. "Promoting safe walking and cycling to improve public health: lessons from The Netherlands and Germany" American Journal of Public Health, 93: 1509-1516.

Rogers, W.V.H. (ed.), 2001. Damages for non-pecuniary loss in a comparative perspective. New York: Springer.

Santolino, M. 2010. "Determinants of the decision to appeal against motor bodily injury judgements made by Spanish trial courts" International Review of Law and Economics, $30,37-45$.

Santolino, M., C. Bolance, and M. Alcañiz, 2012. "Factors affecting hospital admission and recovery stay duration of in-patient motor victims in Spain" Accident Analysis and Prevention, 49: 512-519.

Santolino, M., and M. Söderberg, 2012. "Modelling Appelate Courts' responses in motor injury disputes" European Journal of Law and Economics, doi: $10.1007 / \mathrm{s} 10657-012-9362-\mathrm{z}$.

Scheike, T., and M.-J. Zhang, 2008. "Flexible competing risk regression modeling and goodness-of-fit" Lifetime Data Analysis, 14 (4): 464-483. 
Scheike, T., M.-J. Zhang, and T. Gerds, 2008. "Predicting cumulative incidence probability by direct binomial regression" Biometrika, 95 (1): 205-220.

Scheike, T., and M.-J. Zhang, 2011. "Analyzing Competing Risk Data Using the R timereg Package" Journal of Statistical Software, 38 (2): 1-15.

Shavell, S., 2004. Foundations of economic analysis of law. Cambridge, MA: Harvard University Press.

Sobel, J., and I. Takahashi, 1983. "A multi-stage model of bargaining" Review of Economic Studies, 53 (2): 709-724.

Spier, K., 1992. "The Dynamics of Pretrial Negotiation" Review of Economic Studies, 59: 93-108.

Spier, K., 2003. "The use of 'most-favored-nation' clauses in settlement litigation" RAND Journal of Economics, 34 (1): 78-95. 

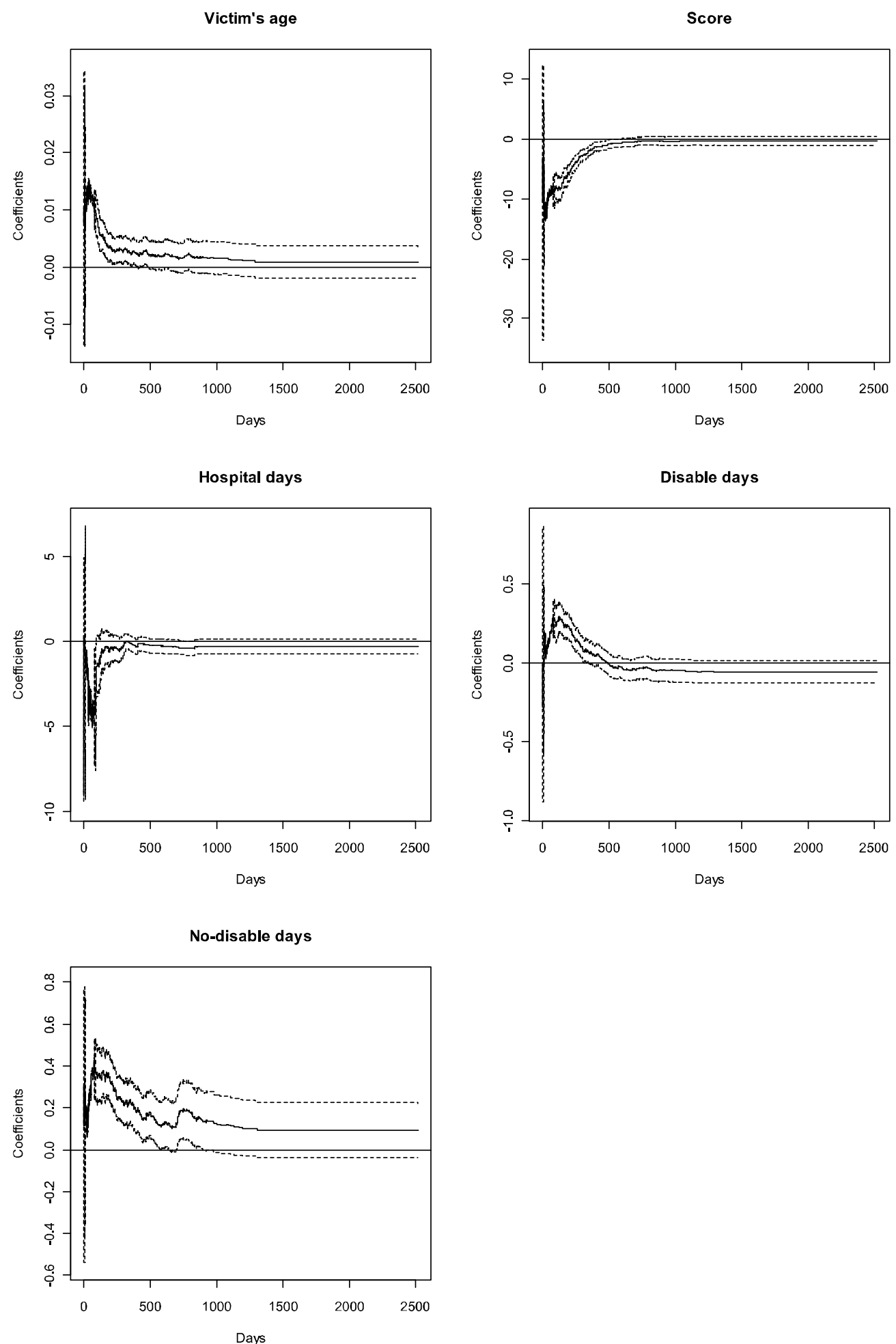